\title{
Influence of Epimedium koreanum on the performance of laying hens, egg quality, and fat soluble vitamin and cholesterol contents in the yolk
}

\author{
Ki-Moon Park', Yan-Hua Jin', Kyun-Taek Lee', Won-Ik Lee', Sung-Woo Nam ${ }^{1}$ and Yung-Keun \\ $\operatorname{Han}^{1^{*}}$ \\ ${ }^{1}$ Department of Food Science and Biotechnology, Sungkyunkwan University, Suwon 440-746, Korea. \\ ${ }^{2}$ School of Chemical Engineering, Sungkyunkwan University, Suwon 440-746, Korea.
}

Accepted 26 August, 2010

\begin{abstract}
This study was conducted to evaluate the effects of feeding Epimedium koreanum to laying hens on performance, as well as to determine its effects on interior and exterior egg quality along with fat soluble vitamin and cholesterol contents in the egg yolk. The experimental diets contained $0.0,1.0,5.0$, or 10.0 $\mathrm{g} / \mathrm{kg} \mathrm{E}$. koreanum. No significant changes were observed in the rate of egg production, with all treatments exceeding $95 \%$. Linear increases in egg weight and mass $(p<0.01)$ were found with dietary $E$. koreanum supplementation. A dramatic increase $(p=0.05)$ was found in the number of extra large $(60$ to $70 \mathrm{~g})$ size eggs with a concomitant reduction $(p=0.06)$ in the number of small $(50$ to $55 \mathrm{~g})$ size eggs. Feed consumption and feed conversion were cubically $(p<0.01)$ affected by $E$. koreanum supplementation. Albumen weight and yolk color linearly increased $(p<0.01)$. The percentage of albumen linearly increased $(p<0.01)$ whereas yolk percentage decreased $(p<0.01)$. Vitamin $E$ content in the egg yolk was quadratically $(p=0.02)$ affected by the treatments. In addition, cholesterol content of the egg yolks was quadratically $(p<0.01)$ increased. In conclusion, dietary inclusion of $E$. koreanum can have beneficial effects on the performance of laying hens in terms of improving egg weight, albumin weight, yolk color, and vitamin $E$ content. However, these advantages may be more than offset by a significant increase in the cholesterol content of the egg yolk.
\end{abstract}

Key words: Epimedium koreanum, layer, egg quality, egg production, vitamin, cholesterol.

\section{INTRODUCTION}

Epimedium is a genus of about sixty or more species of herbaceous flowering plants in the family Berberidaceae, and commonly known as Barrenwort, Bishop's Hat, Fairy Wings, Horny Goat Weed, Rowdy Lamb Herb, or Ying Yang Huo. It is widely used as a traditional medicinal herb in China, Korea, and Japan (Yang, 1985). The major pharmacologically active component of this herb is icariin (Liu and Xu, 1984) This compound can improve the condition of reproductive organs (Liu et al., 2005; Zhao et al., 2006) and has antioxidant effects (Xie, 2008),

${ }^{*}$ Corresponding author. E-mail: y.k.han@skku.edu. Tel: +82-31-290-7904. Fax: +82-31-299-4144. potential activity against osteoporosis (Huang, et al., 2007;Zhang et al., 2008), and enhances immune function (Luo et al., 2009; Zhang et al., 2009). It also raises ovarian and uterine weight and increases days of oestrus ( $\mathrm{Ye}$ and Lou, 2005) and weight gain in mice (Zhao et al., 2006). Such studies showed that $E$. koreanum could be considered as an alternative natural growth promoter for poultry.

Although $E$. koreanum is a potent performance modifier, its role in laying hens has not been studied. Energy metabolism and hormonal conditions strictly control egg production in hens. Differences in laying performance have been related to differences in plasma levels of reproductive hormones such as luteinizing hormone (LH), folliclestimulating hormone (FSH), and progesterone (Wilson, 
Table 1. Ingredients and analyzed chemical composition of the formulated basal diet ( $\mathrm{g} / \mathrm{kg}$ as-fed basis).

\begin{tabular}{lclc}
\hline Yellow corn, USA & $\mathbf{5 0 4 . 5}$ & Moisture & $\mathbf{1 2 2 . 2}$ \\
\hline Wheat, EU & 80.0 & Ether extract & 39.7 \\
Lupin kernel & 20.0 & Crude protein & 170.5 \\
Soybean meal & 184.0 & Crude fiber & 27.2 \\
Maize gluten meal & 29.0 & Ash & 132.8 \\
DDGS, USA & 40.0 & Ca & 40.8 \\
Meat and bone meal & 25.0 & $\mathrm{P}$ & 4.4 \\
Animal fat & 8.0 & MEn, MJ/kg (calculated) & 11.62 \\
Sodium bicarbonate & 0.6 & Lysine & 8.5 \\
L-Lysine HCl & 0.5 & Methionine & 4.3 \\
Methionine & 1.7 & Methionine + Cystine & 7.2 \\
Limestone & 85.6 & & \\
Oyster shell & 15.0 & & \\
Phytase, Optiphos-1000R & 0.50 & & \\
Carbohydrase, EndopowerR & 1.00 & & \\
Premix & 2.36 & & \\
Choline & 0.24 & & \\
Salt & 2.0 & & \\
\hline
\end{tabular}

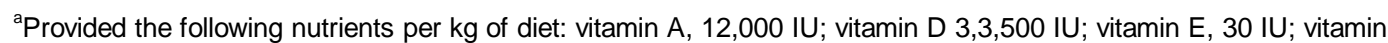
$\mathrm{K}$ 3, $3.0 \mathrm{mg}$; vitamin B1, $3.0 \mathrm{mg}$; vitamin B2, $7.0 \mathrm{mg}$; vitamin B6, $5.0 \mathrm{mg}$; vitamin B12, $0.025 \mathrm{mg}$; niacin, $40.0 \mathrm{mg}$; patothenic acid, $10 \mathrm{mg}$; folic acid, $1.0 \mathrm{mg}$; biotin, $0.15 \mathrm{mg}$; Fe, $75.0 \mathrm{mg}$; Zn, $97.5 \mathrm{mg}$; Mn, $97.5 \mathrm{mg}$; Cu, $7.5 \mathrm{mg}$; I, 1.5 $\mathrm{mg}$; Se, $0.2 \mathrm{mg}$.

1978; Wang and Johnson, 1993; Vanmontfort et al., 1995; Onagbesan et al., 2006). The aim of the present study was to evaluate whether the supplementation of a diet with $E$. koreanum may assist in laying hen performance and to determine its effects on interior and exterior egg quality as well as fat soluble vitamin and cholesterol contents in the egg yolk.

\section{MATERIALS AND METHODS}

\section{Preparation of E. koreanum}

The E. koreanum used in the present experiment was obtained from Yaksan Farmer's Cooperation (Wando, Korea) and is marketed under the name Ying Yang Huo. All parts of the E. koreanum were air dried and then ground to a fine powder using an electric blender. The average icariin content of the E. korenum was $7.47 \mathrm{mg} / \mathrm{g}$.

\section{Animals and housing}

One-hundred and twenty-eight, 18 week-old Lohmann Brown-Lite layers were obtained from a commercial source (Join farm, Choongju, Korea). After 6 weeks of adaptation, 64 hens with an average laying rate of $96.4 \pm 6.95 \%$ (mean \pm S.D.) were selected and allocated randomly into 4 treatments, with 8 replicates per treatment and 2 hens per replicate. A basal diet (Table 1) was fed in mash form and all nutrient levels met or exceeded the nutrient requirements suggested in the Lohmann Brown Management Guide (Lohmann Tierzucht GmbH, 2008). The four experimental groups received an identical basic mixture supplemented with different concentrations of E. koreanum $(0 \%, 0.1$, 0.5 and $1.0 \%$ ). All hens were housed in windowless and environmentally controlled rooms and offered feed and water ad libitum. The cages were galvanized metal wire (approximately $25 \times 35 \times 50 \mathrm{~cm}$ ) in double-decker rows providing $430 \mathrm{~cm}^{2} /$ hen. For this experiment, one upper deck of cages and one lower

deck of cages were used. Each cage had a nipple waterer. A continuous plastic feed trough was divided by replicate to insure that the hens were not able to consume feed assigned to the adjoining replicate. A wire egg collector was installed in front of the cage to prevent eggs from separate replicates from being mixed. The room temperature was kept at $21-23^{\circ}$ and the light cycle consisted of $16 \mathrm{~h}$ of light (incandescent lighting, $10 \mathrm{Ix}$ ) and $8 \mathrm{~h}$ of dark. All procedures used in this experiment were approved by the Animal Ethics Committee of Sungkyunkwan University and by the Guidelines for the Care and Use of Animals in Research (Korean Ministry for Food, Agriculture, Forestry and Fisheries, 2008).

\section{Sampling and analyses}

The eggs were collected and weighed every day and feed consumption was measured on a weekly basis. Egg production was calculated on a replicate basis. Egg weight ( $\mathrm{g}$ of egg/hen per day) and feed conversion ( $\mathrm{g}$ of feed/g of egg) were calculated from egg production, egg weight, and feed consumption. Egg components were measured using two eggs of average weight in a week, from each cage on the last 2 days of each week. Yolk color and Haugh units were measured using an egg multi tester EMT-5200 (Robotmation Co. Ltd., Tokyo, Japan). Haugh units were calculated from the records for egg weight and albumen height using the formula: $\mathrm{HU}=100 \log 10(\mathrm{H}-1.7 \mathrm{~W} 0.37+7.56)$, where $\mathrm{HU}=$ Haugh unit, $\mathrm{H}=$ height of the albumen $(\mathrm{mm})$, and $\mathrm{W}=$ egg weight (g). The yolks were separated from the tester tray (yolk, albumen, and tray) using a Teflon spoon. Before yolk weight was determined, the chalaza was removed by a spatula. The shells were weighed without drying. Albumen weight was calculated by subtracting the weight of the tester tray. Daily egg content was calculated (\% egg production $\mathrm{x}$ (daily yolk weight + daily albumen weight) from egg production, yolk weight, and albumen weight.

Total cholesterol was determined without saponification according to Zhang et al. (1999). 
Table 2. Performance of laying hens fed experimental basal diets supplemented with $E$. koreanum.

\begin{tabular}{|c|c|c|c|c|c|c|c|c|}
\hline & \multicolumn{4}{|c|}{ Level of E. koreanum } & \multirow{2}{*}{ SEM } & \multicolumn{3}{|c|}{ P-value } \\
\hline & $0 \mathrm{~g} / \mathrm{kg}$ & $1.0 \mathrm{~g} / \mathrm{kg}$ & $5.0 \mathrm{~g} / \mathrm{kg}$ & $10.0 \mathrm{~g} / \mathrm{kg}$ & & $\mathbf{L}$ & $\mathbf{Q}$ & $\mathbf{C}$ \\
\hline Egg production (\%) & 97.5 & 96.5 & 95.4 & 98.5 & 1.12 & 0.68 & 0.07 & 0.40 \\
\hline Egg weight (g/hen/d) & 54.7 & 54.9 & 55.0 & 58.4 & 0.81 & $<0.01$ & 0.05 & 0.26 \\
\hline Egg content (g/hen/d) & 47.0 & 47.7 & 47.7 & 50.7 & 0.72 & $<0.01$ & 0.10 & 0.27 \\
\hline Feed consumption (g/hen/d) & 106.5 & 107.1 & 103.5 & 106.8 & 0.82 & 0.23 & 0.10 & $<0.01$ \\
\hline Feed conversion ( $\mathrm{g}$ feed/g egg) & 1.96 & 1.97 & 1.89 & 1.86 & 0.025 & 0.08 & 0.48 & $<0.01$ \\
\hline
\end{tabular}

The extraction and HPLC analysis of fat soluble vitamins in the egg yolk were performed using very similar methods of Gong and $\mathrm{Ho}$ (1997) used for analysis in milk.

The feed was analyzed in triplicate according to AOAC methods (1995). Analyses were conducted for moisture (method 930.15), ether extract (method 920.39), crude protein (method 984.13), crude fiber (method 978.10), and ash (method 942.05). Calcium was determined by a Shimazu AA625 Atomic Absorption Spectrophotometer (Shimazu, Kyoto, Japan), and phosphorus was analyzed using a UV-vis. Spectrophotometer (Hitachi, Tokyo, Japan). An amino acid analysis of the feed was performed using a L8500-Hitachi Amino Acid Analyzer (Hitachi, Tokyo, Japan) after hydrolysis for $24 \mathrm{~h}$ in $6 \mathrm{~N} \mathrm{HCl}$. Performic acid (85\%) hydrolysis was conducted to analyze sulfur-containing amino acids. Eggs from each cage were sorted by six size groups (jumbo, extra large, large, medium, small, and miniature)

\section{Statistical analysis}

The data were analyzed as a randomized block design (Snedecor and Cochran, 1989), using the appropriate Genera Analysis of Variance procedures of STATISTIX (1996). The hens were blocked on the basis of hen-day egg production during the adaptation period and the cage was considered the experimental unit for all analyses. The model included the effects of replication (that is, block), treatment, and replication $x$ treatment (error). Moreover, we constructed polynomial contrasts to determine the nature of response variables to increasing levels of supplemental E. koreanum.

\section{RESULTS AND DISCUSSION}

The effects of different levels of dietary E. koreanum on performance are presented in Table 2. No significant changes were observed for rate of egg production with increasing dietary $E$. koreanum. However, a quadratic trend $(p=0.07)$ existed for egg production. Since the rate of egg production exceeded $95 \%$ for all treatments, there was a very small window of opportunity for $E$. koreanum to increase the rate of production. In commercial farms, peak production usually occurs when hens reach 24 to 26 weeks of age, and production steadily declines until the flock is taken out of production at approximately 76 weeks of age (Bell, 2002). The present study was conducted close to the period of peak production, and it would be interesting to repeat the study to determine whether or not E. koreanum has any impact on the productivity of laying hens during later stages of the production cycle.

Linear increases in egg weight and egg content ( $p$ $<0.01$ ) were found with increasing dietary $E$ Koreanum. The general increases in egg weight and content were associated with a dramatic increase $(P=0.05)$ in the number of extra large (60 - $70 \mathrm{~g}$ ) size eggs with a concomitant reduction ( $\mathrm{p}=$ 0.06 ) in the number of small (50 - $55 \mathrm{~g}$ ) size eggs (Table 5). Since many countries pay a premium for larger sized eggs (Food and Agriculture Organization of the United Nations, 2003), there may be an economic incentive for producers to utilize E. Koreanum as a means of increasing the percentage of large size eggs produced. Feed consumption and feed conversion were cubically ( $p$ $<0.01$ ) affected by $E$. koreanum supplementation. As dietary $E$. koreanum increased, feed conversion improved because egg weight increased significantly $(p<0.01)$ with increased dietary levels of $E$. koreanum. In contrast to our result, Botsoglou et al. (2005) found that the supplementation of rosemary, oregano and saffron to a layer diet had no significant effect on egg production, feed intake and feed conversion ratio. The determined egg components and quality for laying hens fed the experimental basal diet supplemented with $E$. koreanum are shown in Table 3. Albumen weight and yolk color linearly increased $(p<0.01)$ as dietary $E$. koreanum increased. This is consistent with data from Ghasemi et al. (2010) who reported that yolk color responded linearly with increasing levels of medicinal herbs. Poltowicz and Wezyk (2001) had also showed that the herbs used significantly increased yolk color intensity in the experimental groups. The percentage of albumen linearly and cubically increased $(p<0.01)$, whereas yolk percentage linearly and cubically decreased $(p$ $<0.01$ ) as dietary $E$. koreanum level increased. Yolk weight was cubically affected $(p<0.01)$ by increases of dietary $E$. koreanum. A quadratic increase in egg shell weight $(p<0.01)$ was found with increasing dietary $E$. koreanum, whereas egg shell percentage was not affected by the dietary 
Table 3. Egg components and egg quality for laying hens fed experimental basal diets supplemented with E. koreanum.

\begin{tabular}{|c|c|c|c|c|c|c|c|c|}
\hline & \multicolumn{4}{|c|}{ Level of E. koreanum } & \multirow{2}{*}{ SEM } & \multicolumn{3}{|c|}{ P-value } \\
\hline & $0 \mathrm{~g} / \mathrm{kg}$ & $1.0 \mathrm{~g} / \mathrm{kg}$ & $5.0 \mathrm{~g} / \mathrm{kg}$ & $10.0 \mathrm{~g} / \mathrm{kg}$ & & $\mathbf{L}$ & $\mathbf{Q}$ & C \\
\hline Albumin weight (g) & 33.7 & 34.0 & 34.8 & 36.8 & 0.58 & $<0.01$ & 0.14 & 0.76 \\
\hline Albumin (\%) & 61.4 & 60.8 & 62.8 & 62.0 & 0.30 & $<0.01$ & 0.68 & $<0.01$ \\
\hline Yolk weight (g) & 13.4 & 13.7 & 12.9 & 13.9 & 0.24 & 0.38 & 0.16 & $<0.01$ \\
\hline Yolk (\%) & 25.8 & 25.1 & 24.5 & 25.0 & 0.28 & $<0.01$ & 0.72 & $<0.01$ \\
\hline Egg shell weight $(\mathrm{g})$ & 7.6 & 7.3 & 7.2 & 7.7 & 0.16 & 0.93 & 0.01 & 0.45 \\
\hline Egg shell (\%) & 12.8 & 13.1 & 12.7 & 13.0 & 0.14 & 0.74 & 0.87 & 0.05 \\
\hline Yolk colour & 6.9 & 6.9 & 7.3 & 7.3 & 0.10 & $<0.01$ & 0.82 & 0.06 \\
\hline Haugh units & 88.7 & 87.7 & 88.8 & 88.0 & 0.73 & 0.73 & 0.88 & 0.23 \\
\hline
\end{tabular}

Table 4. Fat soluble vitamin and cholesterol content in egg yolk for laying hens fed experimental basal diets supplemented with E. koreanum.

\begin{tabular}{|c|c|c|c|c|c|c|c|c|}
\hline & \multicolumn{4}{|c|}{ Level of E. koreanum } & \multirow{2}{*}{ SEM } & \multicolumn{3}{|c|}{ P-value } \\
\hline & $0 \mathrm{~g} / \mathrm{kg}$ & $1.0 \mathrm{~g} / \mathrm{kg}$ & $5.0 \mathrm{~g} / \mathrm{kg}$ & $10.0 \mathrm{~g} / \mathrm{kg}$ & & $\mathbf{L}$ & $\mathbf{Q}$ & $\mathbf{C}$ \\
\hline Vitamin A (mg/100 g) & 0.93 & 0.94 & 0.95 & 0.94 & 0.005 & 0.13 & 0.46 & 0.37 \\
\hline Vitamin D $(\mu \mathrm{g} / 100 \mathrm{~g})$ & 43.9 & 43.9 & 44.1 & 43.9 & 0.24 & 0.85 & 0.76 & 0.59 \\
\hline Vitamin E (mg/100 g) & 1.95 & 1.98 & 2.02 & 1.98 & 0.015 & 0.30 & 0.02 & 0.14 \\
\hline Cholesterol $(\mathrm{mg} / 100 \mathrm{~g})$ & 1106 & 1323 & 1346 & 1247 & 51.6 & 0.06 & $<0.01$ & 0.75 \\
\hline
\end{tabular}

treatments. The Haugh unit was also not affected by the addition of E. koreanum.

The effects of $E$. koreanum supplementation on the fat-soluble vitamin content of the egg yolk are presented in Table 4. Vitamin E $(p=0.02)$ content was quadratically affected by the dietary treatments. Eggs are considered a good source of Vitamin $E$ in the human diet, as two large eggs can contribute $6 \%$ of the recommended daily allowance of this nutrient (Applegate, 2000).

Increases as a result of E. koreanum supplementation can enhance the reputation of eggs as a good source of vitamin E. There was a quadratic $(p<0.01)$ increase in the cholesterol content of the egg yolks with increasing levels of $E$. koreanum supplementation (Table 5). This finding has broad implications for the potential adoption of E. koreanum as a feed additive for use in the layer industry, as consumers are very concerned about the cholesterol content of foods (Applegate, 2000). This concern is based on more than 40 years of speculation regarding the association between the consumption of high cholesterol diets, blood cholesterol, and coronary heart disease (Masironi, 1970; Dawber et al., 1982; Paik and Blair, 1996 Steinberg, 2004). Current human dietary guidelines recommended that in order to reduce the risk of cardiovascular disease, consumers should limit their intake of dietary cholesterol to less than 300 mg per day (American Heart Association Nutrition
Committee, 2006). For most people trying to lowerblood cholesterol, however, limiting saturated fat is more effective than limiting cholesterol intake. Most foods that are high in cholesterol are also high in saturated fat, but eggs are an exception. An egg contains only one gram of saturated fat. Eggs are a valuable part of the diet because they are a source of high quality protein and other nutrients.

\section{Conclusion}

The effects of dietary E. koreanum supplementation on performance and egg quality parameters of laying hens have not been previously reported. The 
Table 5. Exterior egg quality for laying hens fed experimental basal diets supplemented with $E$. koreanum

\begin{tabular}{|c|c|c|c|c|c|c|c|c|}
\hline & \multicolumn{4}{|c|}{ Level of E. koreanum } & \multirow{2}{*}{ SEM } & \multicolumn{3}{|c|}{ P-value } \\
\hline & $0 \mathrm{~g} / \mathbf{k g}$ & $1.0 \mathrm{~g} / \mathrm{kg}$ & $5.0 \mathrm{~g} / \mathrm{kg}$ & $10.0 \mathrm{~g} / \mathrm{kg}$ & & $\mathbf{L}$ & $\mathbf{Q}$ & C \\
\hline Defected eggs (\%) & 0.96 & 1.00 & 2.50 & 1.21 & 0.826 & 0.55 & 0.43 & 0.26 \\
\hline Dirty eggs (\%) & 4.75 & 3.62 & 3.00 & 2.53 & 1.371 & 0.24 & 0.81 & 0.95 \\
\hline \multicolumn{9}{|l|}{ Egg grade $(\%)$} \\
\hline Jumbo (70 $\mathrm{g}$ and over) & 1.13 & 0.98 & 1.12 & 0.64 & 0.503 & 0.55 & 0.75 & 0.68 \\
\hline Extra large $(65-70 \mathrm{~g})$ & 1.32 & 3.59 & 6.74 & 8.47 & 2.629 & 0.05 & 0.92 & 0.85 \\
\hline Large $(60-65 \mathrm{~g})$ & 14.73 & 19.08 & 23.81 & 29.07 & 5.984 & 0.09 & 0.94 & 0.99 \\
\hline Medium (55-60 g) & 42.11 & 37.08 & 33.98 & 45.42 & 5.059 & 0.76 & 0.11 & 0.58 \\
\hline Small $(50-55 \mathrm{~g})$ & 30.58 & 35.35 & 23.77 & 14.94 & 6.687 & 0.06 & 0.32 & 0.53 \\
\hline Miniature (50 $\mathrm{g}$ and under) & 10.13 & 3.93 & 10.58 & 1.46 & 3.982 & 0.29 & 0.72 & 0.12 \\
\hline
\end{tabular}

improving egg weight, albumin weight, yolk color, and vitamin E content. However, these advantages may be more than offset by a significant increase in the cholesterol content of the egg yolk. However, further research needs to be conducted in future with emphasizing utilization of $E$. koreanum and its appropriate concentration.

\section{REFERENCES}

American Heart Association Nutrition Committee (2006). Diet and lifestyle recommendations revision 2006: A scientific statement from the American Heart Association Nutrition Committee. Circulation, 114: 82-96.

AOAC (1995). Official Methods of Analysis. 16th ed. Association of Official Analytical Chemists. Arlington, VA, p. 225.

Applegate $E$ (2000). Nutritional and functional roles of eggs in the diet. J. Am. Coll. Nutr., 19: 495S-498S.

Bell DD (2002). Egg production and egg weight standards for table-egg layers. In: Bell DD, Weaver WD (eds) Commercial Chicken Meat and Egg Production. 5th Ed. Kluwer Academic Publishers, Norwell, Massachusetts, pp. 1079-1090.

Botsoglou NA, Florou-Paneri P, Botsoglou E, Datos V, Giannenenas I, Koidis A, Mitrakos P (2005). The effect of feeding rosemary, oregano, saffron and $\alpha$-tocopheryl acetate on hen performance and oxidative stability of eggs. S. Afr. Anim. Sci., 35: 143-151.
Dawber TR, Nickerson RJ, Brand FN, Pool J (1982). Eggs, serum cholesterol, and coronary heart disease. Am. J. Clin.

Nutr., 36: 617-625.

Food, Agriculture Organization of the United Nations (2003). Egg production. In: Egg Marketing-A Guide for the Production and Sale of Eggs, FAO Agricultural Services Bull., 150: 1-27.

Ghasemi R, Zarei M, Torki M (2010). Adding medicinal herbs including garlic (Allium sativum) and Thyme (Thymus vulgaris) to diet of laying hens and evauating productive performance and egg quality characterisctis. Am. J. Anim. Veterinary Sci., 5 151-154.

Gong BY, Ho JW (1997). Simutaneous separation and detection of ten common fat-soluble vitamins in milk. J. Liq Chromatography Related Technol., 20: 2389-2397.

Huang J, Yuan L, Wang X, Zhang TL, Wang K (2007). Icariin and its glycosides enhance osteoblastic, but suppress osteoclastic differentiation and activity in vitro. Life Sci., 81: 832-840.

Korean Ministry for Food, Agriculture, Forestry, Fisheries (2008). Guidelines for the Care and Use of Animals in Research Korean Ministry for Food, Agriculture, Forestry and Fisheries, Seoul, Korea.

Liu J, Lou YJ (1984). Determination of icariin and metabolites in ra serum by capillary zone electrophoresis; Rat pharmacokinetic studies after administration of icariin. J. Pharm. Biomed. Anal., 36: 365-370.

Liu CR, Xu LX (1984). Analysis of active ingredients of traditional Chinese herbal drug. Assay of icariin in Epidemium. Chin. J. Pharm. Anal., 4: 81-84.

Liu WJ, Xin ZC, Xin H, Yuan YM, Tian L, Guo YL (2005). Effects of icariin on erectile function and expression on nitric oxide synthase isoforms in castrated rats. Asian. $J$. Androl., 7: 381-388.

Lohmann Tierzucht GmbH (2008). Layer Management Guide Lohmann Brown Classic.

Luo Y, Shao Y, Gu X, Li X (2009). Effects of Epimedium Herb Polysaccharides on the Immunity Function and Vaccination in Chickens. China Poult., 31: 22-26.

Masironi R (1970). Dietary factors and coronary heart disease. Bull. WHO, 42: 103-114.

Onagbesan OM, Metayer S, Tona K, Williams J, Decuypere E, Bruggeman V (2006). Effects of genotype and feed allowance on plasma luteinizing hormones, follicle-stimulating hormones, progesterone, estradiol levels, follicle differentiation, and egg production rates of broiler breeder hens. Poult. Sci., 85: 1245-1258.

Paik IK, Blair R (1996). Atherosclerosis, cholesterol and egg: A review. Asian-Aust. J. Anim. Sci., 9: 1-25.

Poltowicz K, Wezyk S (2001). Effect of herb supplementation in the feeding of laying hens on their productivity and egg quality. Roczniki Naukowe Zootechniki, 28: 215-225.

Snedecor GW, Cochran WG (1989). Statistical Methods. 7th ed. The lowa State University Press. Ames, lowa, pp881

STATISTIX (1996). Statistix for Windows, User's Manual. Analytical Software. Tallahassee, Florida.

Steinberg D (2004). The pathogenesis of atherosclerosis. An interpretive history of the cholesterol controversy: Part I. J. Lipid Res., 45: 1583-1593.

Vanmontfort D, Berghman LR, Rombauts L, Verhoeven G, Decuypere $E$ (1994). Changes of immunoreative inhibin, folicle stimulating hormone, luteinizing hormone, and progesterone in 
plasma after short-term food deprivation and during the ovulatory cycle of domestic hen. Gen. Comp. Endocrinol., 95: 
correlated with a decrease in ovulation rate in the domestic hen. Gen. Comp. Endocrinol., 91: 52-58.

Wang ZQ, Loy YJ (2004). Proliferation-stimulating effects of icariin and desmethylicariin in MCF-7 cells. Eur. J. Pharmacol., 504: 147-153.

Wilson SC (1978). Relationship between plasma concentration of luteinizing hormone and intensity of lay in the domestic hen. Br. Poult. Sci., 19: $643-650$

Xie JP (2008). Study on extraction and antioxidation effects of flavonoids from E. wushanense. J. Anhui. Agri. Sci., 36: 15532-15534.

Yang ZZ (1985). Clinical applications of Yingyanghuo. J. Trad. Clin. Med., 20: 478-480.

Ye HY, Lou YJ (2005). Estrogenic effects of two derivatives of icariin on human breast cancer MCF-7 cells. Phytomedicine, 12: 735-741.

Zhang RZ, Li L, Liu ST, Chen RM, Rao PF (1999). An improved method of cholesterol determination in egg yolk by HPLC. J. Food Biochem., 23: 351-361.
Zhang DW, Cheng Y, Zhang JC, Wang XL, Wang NL, Chen Y, Yang MS, Yao XS (2008). Synergistic effect of trace elements and flavonoids from Epidenium koreanum Nakai on primary osteoblasts, 53: 347-356.

Zhang G, Gong S, Yu D, Yuan H (2009). Propolis and herba Epimedii extracts enhance the non-specofic immune response and disease resistance of Chinese sucker, Myxocyprinus asiaticus. Fish and Shellfish Immunol., 26: 467-472.

Zhao PW, Wang DW, Wang LQ, Niu JZ, Wang JF (2006). Screening of ten kinds of Chinese herbal drugs including Herba Epimedii with estrogenic effects by uterus growth test in mice. J. Beijing Univ. Trad. Chinese Med., 29: 686-689. 